\title{
The effects of shared decision-making compared to usual care for prostate cancer screening decisions: a systematic review and meta-analysis
}

Nahara Anani Martínez-González (iD, Stefan Neuner-Jehle, Andreas Plate, Thomas Rosemann and Oliver Senn

\begin{abstract}
Background: Shared decision-making (SDM) is recommended for men facing prostate cancer (PC) screening decisions. We synthesize the evidence on the comparative effectiveness of SDM with usual care.

Methods: We searched academic and grey literature databases, and other sources for primary randomised controlled trials (RCTs) published in English comparing SDM to usual care and conducted in primary and specialised care. We assessed the individual study risk of bias, and calculated the study-specific and pooled relative risks (RR) or standardised mean differences (SMD) [with 95\% confidence intervals (CI)] to perform random-effects meta-analyses for SDM-related and patient outcomes.

Results: Four RCTs comparing SDM to usual care, involving 1760 men, were included. SDM improved knowledge (SMD 0.23, 95\%Cl 0.02 to $0.43 ; 2 \mathrm{RCTs}$ ), but was not different to usual care in reducing either patient participation in prostate-specific antigen (PSA) testing (RR 1.03, 95\%Cl 0.90 to $1.19 ; 2$ RCTs) or decisional conflict (SMD $-0.04,95 \% \mathrm{Cl}-0.23$ to $0.15 ;$ SMD $-0.05,95 \% \mathrm{Cl}-0.24$ to $0.14 ; 2$ RCTs). Individual trial estimates (46.7\%) also suggest that SDM may reduce or neutralise physicians' tendency for PSA screening, and may improve the accuracy of patients' perception of lifetimerisks and men's views towards screening. There was no evidence on the effects of SDM on health outcomes. The studies represent various interventions and outcomes and are prone to risk of bias.

Conclusions: There is currently insufficient evidence to support a clear association of SDM on patient- and SDMrelated outcomes for decisions about PSA testing. Further research needs to assess the clinical effectiveness of SDM using well-defined SDM interventions and outcomes. It should address the absence of evidence, particularly on health outcomes.
\end{abstract}

Keywords: Systematic review, Meta-analysis, Shared decision-making, Prostate Cancer, Screening, Randomised controlled trials

\footnotetext{
* Correspondence: Nahara.Martinez@usz.ch

Institute of Primary Care, University of Zurich and University Hospital of

Zurich, Pestalozzistrasse 24, CH-8091 Zurich, Switzerland
}

(c) The Author(s). 2018, corrected publication November/2018. Open Access This article is distributed under the terms of the Creative Commons Attribution 4.0 International License (http://creativecommons.org/licenses/by/4.0/), which permits

unrestricted use, distribution, and reproduction in any medium, provided you give appropriate credit to the original author(s) and the source, provide a link to the Creative Commons license, and indicate if changes were made. The Creative Commons Public Domain Dedication waiver (http://creativecommons.org/publicdomain/zero/1.0/) applies to the data made available in this article, unless otherwise stated. 


\section{Background}

Prostate cancer (PC) is the second most commonly diagnosed non-skin malignancy and the fifth leading cancer-related cause of death for men worldwide [1, 2]. PC incidence varies mainly by age, race/ethnicity and family history $[2,3]$. It continues to rise, mostly in Western developed countries $[1,4]$ and is expected to increase to 1.7 million cases and 499,000 new deaths by 2030 globally [2].

Screening for PC aims to diagnose the disease at an early stage when the chances of successful treatment are higher, thus increasing the possibility of cure. Indeed the widespread use of screening tests, especially prostate-specific antigen (PSA) in the general population, has improved early PC detection, thereby increasing the incidence of diagnosed PC. The balance between the benefits and harms of screening remains controversial however [5]. PC testing has led to false-positive results, complications and over diagnosis (risk estimates: up to $67 \%$ ) that may lead to further unnecessary investigations and overtreatment [6]. Data about the reduction in mortality due to PC screening have also shown conflicting results. Population-based trials have shown no significant differences in PC mortality after 13, 15 or 20 years [7-9], while others showed reduced risks of metastases and PC-specific mortality after 11 and 13 years [10-12]. In addition, treatment for screened-detected PC can lead to potential adverse outcomes (e.g. urinary and erectile dysfunction, loss of fertility, chemotherapy and/or hormone therapy side effects), distress, impaired quality of life, and increased healthcare costs [10, 13, 14]. Guidelines for PC screening consequently vary worldwide. Recommendations for PC testing by some health authorities are becoming more consistent by setting constraints and only screening well-informed men [15-19]. Others have developed specific population-based screening programs [20]. Some others are against population-based screening, but still provide testing on demand [21-23]. In addition, the screening practices for men at risk of PC and the age at which screening should be started for example, are still being debated [24]. These factors, together with the fast-growing availability of cancer testing and treatment technology, make the process of medical decision-making even more challenging for both patients and healthcare professionals (HCP), leading to value-laden decisions that are preference-sensitive.

Shared decision-making (SDM) is viewed as the best practice model for physician-patient-communication regarding preference-sensitive medical decisions [25]. Experts, major task force associations, policy makers and clinical guidelines strongly advocate SDM discussions as a critical step preceding medical decisions for PC screening $[15,17,19,22-24,26]$. SDM may have the potential of reducing the overuse of options with unclear benefits while enhancing the use of beneficial options and reducing variations in practice [27, 28]. To-date, however, there is no single definition of SDM and no consensus on how to integrate SDM in practice resulting in varying levels of SDM implementation. A systematic review showed that key criteria recommended for SDM [29] supporting the principle of deliberation [30] was fulfilled by only $34.8 \%$ of the studies evaluating SDM for decisions about PC screening [31].

Increasing research has focused on the development of decision aids (DAs) as a way to promote informed medical decisions and to improve patient outcomes [32]. Evidence on the effects of SDM is not restricted to DAs however. In addition, provision of DAs does not ensure patient participation in decision-making nor does it warrant an SDM approach to medical decisions. The role of SDM in improving patient outcomes as compared to usual care remains unclear. We sought to evaluate the evidence on the effectiveness of SDM as compared to current clinical practice for patient- and SDM-related outcomes. We focused on the population of men facing preference-sensitive decisions for PC screening.

\section{Methods}

Our study followed a protocol based on the recommendations for systematic reviews of healthcare interventions $[33,34]$ and the PRISMA guidelines (Additional file 1) [35]. The methods to identify and select studies are described in detail elsewhere [31].

\section{Search strategy}

Using terminology compatible with SDM and prostate cancer, we searched for RCTs using MEDLINE Ovid, EMBASE (Elsevier), CINHAL (EBSCOHost), The Cochrane Library (Wiley), PsychINFO (EBSCOHost) and Scopus from the period of database inception up to March 2015 (see Additional file 2). We searched for grey literature using clinical trial registers (clinicaltrials.gov and ISRCTN), the WHO search portal (http://www.who.int/ ictrp/search/en/) and the Ottawa Hospital Research Institute website (http://www.ohri.ca//) by accessing the records between February and August 2016, and searching for the trials registration number in Medline and PubMed. We also searched Google Scholar and the system for Information on Grey Literature in Europe (http://opengrey.eu/). Additionally, we screened the reference lists of included studies, relevant systematic reviews and clinical guidelines. We also contacted (June 2015 to January 2017) the authors of abstracts for which full-text publications could not be located.

\section{Eligibility criteria}

We included peer-reviewed randomised controlled trials (RCTs) published in English, from any country, investigating SDM for PC screening in primary or specialised 
care (general practice, community clinics, ambulatory care, hospital and private care services), which: 1) compared SDM to usual care regardless of the intervention target (patients and/or HCP, surrogates or family members), and 2) reported outcome data in quantitative format. We further limited study eligibility to RCTs that fulfilled the criteria for SDM based on the most prominent SDM framework $[29,36]$ considering bi-directional deliberation as central and mandatory in SDM [37]. As detailed elsewhere, this process led to a set of studies of higher SDM quality [31].

Outcomes' relevance is generally directed by the personalisation of the SDM process, patients' health status and the available choices, resulting in a non-standardised set of outcomes to evaluate the success of SDM. We focused on the outcomes of knowledge, screening participation, risk perception, patient satisfaction, decisional conflict, decisional regret, quality of life, symptoms and mortality.

\section{Selection of studies and data extraction}

Two authors independently screened the titles and abstracts of all citations, and examined the full-text of eligible publications. Data extractions were carried out by one author, and independently verified by a second author. Discrepancies in study selection and data extractions were moderated by a third author. Data were extracted using standardised data collection forms developed a-priori. For each study, one author extracted data elements including the bibliographic details, design, country and setting, characteristics of study populations and interventions, and outcome data. Studies reported across more than one publication were treated as one unit. We used the classification system recommended by Shay and Lafata [38] to group outcomes into Affectivecognitive, Behavioural and Health outcomes.

\section{Study quality}

Two authors independently assessed in duplicate the quality features of the included studies without the calculation of a composite score following available recommendations [34, 39]. Differences were resolved by discussion. We rated the adequacy of the studies' core items for internal validity (risk of bias) including generation of random sequence, concealment of allocation at randomisation, blinding (patients, healthcare providers and outcome assessors), intention-to-treat (ITT) and similarity between groups at baseline. We considered bias due to attrition of at least $20 \%$ to be of significant concern; adequate ITT when authors analysed participants based on their original group allocation; and adequate follow-up if all participants were followed-up for the same length of time. We also assessed whether studies defined primary and secondary outcomes, inclusion and exclusion criteria, 'a-priori' sample size and the type of funding sources.

\section{Statistical analysis}

Where data were sufficiently reported, for each study outcome we calculated the unadjusted risk ratios (RR) or the standard mean differences (SMD) and the 95\% confidence intervals (CI) with RevMan, version 5.3 .5 (http://commu nity.cochrane.org/). We pooled data in meta-analyses when at least two RCTs reported appropriate data. Missing standard deviations (SD) were estimated using established techniques [34]. We report the summary statistics with their 95\% CI, and regard $p<0.05$ as statistically significant. We quantified heterogeneity using the $\mathrm{I}^{2}$ statistic, for which values of $25 \%, 50 \%$, and $75 \%$ represent low, moderate, and high levels of heterogeneity [40]. Data not combined in meta-analyses were analysed based on the individual trial estimates. We anticipated heterogeneity due to diversity in populations and interventions and thus performed all analyses under random-effects [34]. We tabulated the effect sizes and synthesised all results narratively.

\section{Results}

\section{Identification of studies}

Of 270 full-text articles examined in detail, nine fulfilled all SDM criteria. Five of these investigated the comparative effectiveness of SDM with usual care [41-45]. Figure 1 shows the flow of study identification and selection.

\section{Study and population characteristics}

The summary characteristics of the included studies are reported in Table 1. The studies, published between 2003 and 2013, were conducted in the USA $(n=3)$ and Australia $(n=1)$. Three parallel-RCTs $(75 \%)$ comprised 1048 patients individually randomised to intervention groups while one cluster-RCT randomised 712 patients with 120 physicians and 55 waiting areas. Participants were recruited from general or internal medicine primary care clinics including urban/suburban, academic, medical group practices or university-hospital affiliated clinics. All studies defined PC screening as testing with PSA. The men's age range was 54-63 years with a mean age of 59.5 (SD7.5; 3 RCTs) and the target-age for study inclusion was 40-74 years. Patient demographics varied widely across studies. Where reported, $76.6 \%$ (range: 56.6-90.8\%) of men were White, $76.9 \%$ (range: 71.5-80.0\%) were married, 76.45\% (range: $30.4-89.5 \%$ ) had at least high school education, and $46.9 \%$ (range: $42.5-57.5 \%$ ) were in full- or part-time employment. At least $56.7 \%$ of all participating men were screened with PSA before study enrolment, and $12.4 \%$ of men in three RCTs reported a family history of PC. Between 13 and 120 family or internal medicine (i.e. faculty, resident and academic) physicians 


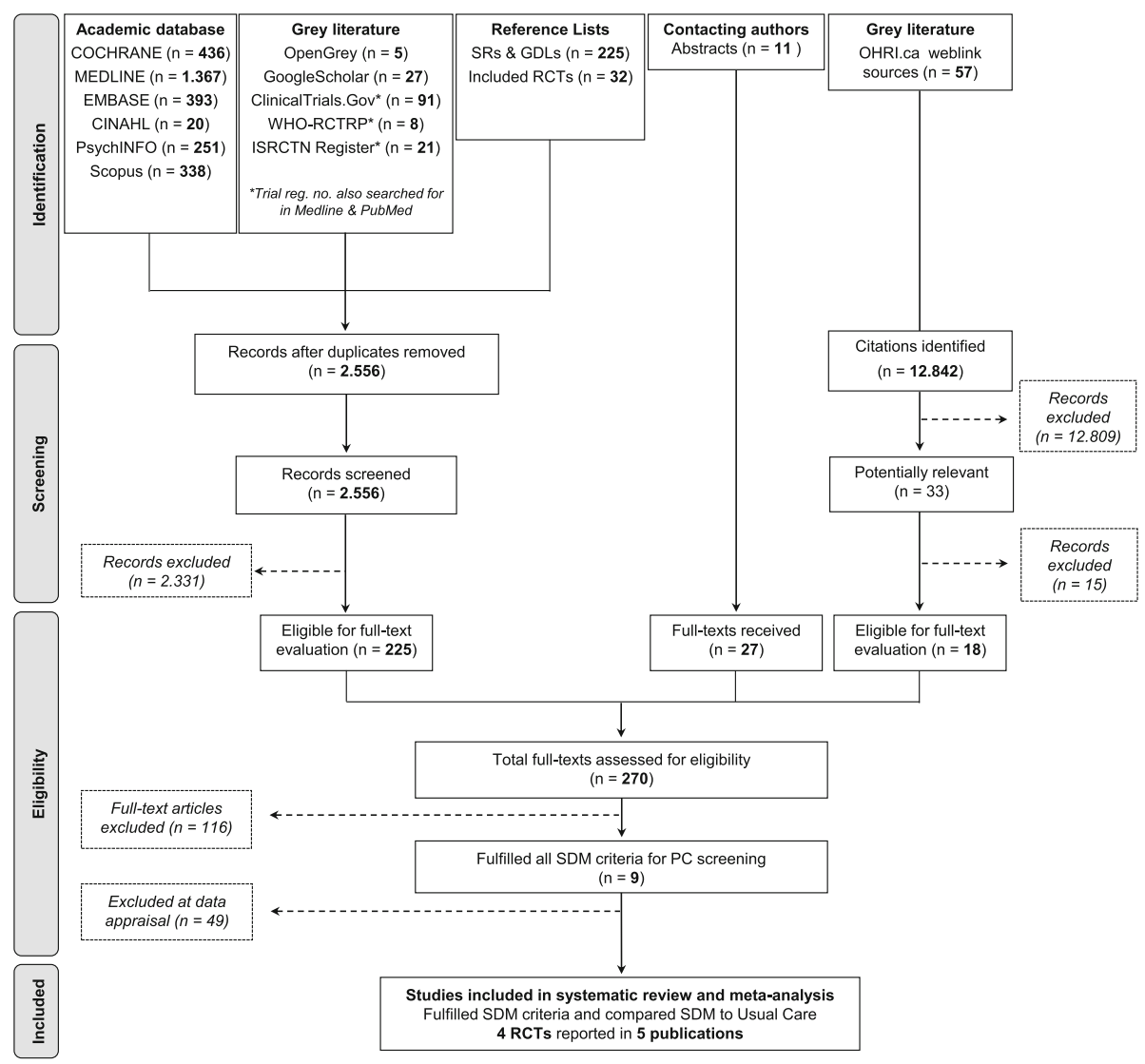

Fig. 1 Identification and selection of studies

participated in the studies and had 2-40 years of experience in two RCTs.

\section{Intervention characteristics}

All RCTs and study interventions aimed at and contained elements to facilitate or foster SDM between patients and physicians (Table 1). All RCTs also fulfilled the three key SDM features [29, 36] and bi-directional deliberation [37] as previously illustrated [31]. The interventions were delivered before decision-making, either within the time of scheduled visits [43, 44] or before consultations [41, 42, 45 ] as an attempt to empower patients and to encourage participation in decision-making. Men were recommended to review the material before consultation $[41,43$, 44], to discuss their concerns with their doctors [45] or were specifically activated [41]. Three RCTs [42-45] used patient-directed interventions, and one RCT [41] used patient-physician targeted interventions. Only one RCT used a multifaceted strategy [41]. The interventions were self-administered, and delivered on-site $[41,45]$ or at home [42-44], in a web-based or (printed) paper-based material or both. Only two RCTs considered healthcare literacy for the development or pilot testing of interventions $[42,45]$. Two RCTs evaluated two different SDM interventions and usual care $[41,43,44]$. Their content included mostly educational information about PC and screening for physicians and patients as well as the links to informational material from established organisations (e.g. the Centers for Disease Control and Prevention). The content of usual care was incompletely described in most studies.

\section{Risk of bias in the methods of included studies}

No trial fulfilled all the core criteria of internal validity, based on current standards [34] (Table 2). The trials were at risk of selection bias as only two (50\%) had adequate random sequence generation and allocation concealment. Studies were also vulnerable to performance and detection biases since blinding of HCP and participants, and outcome assessors were adequate in only two $(50 \%)$ and one (25\%) RCTs respectively. Two RCTs $(50 \%)$ had at least $20 \%$ attrition for some outcomes and only two $(50 \%)$ reported the use of ITT techniques to deal with missing data. One RCT (25\%) was potentially at risk of chance bias although it purposely had more physicians knowing the group in which patients were allocated (ratio of 1:3:3 between groups) in order to free other potential biases. Men in one RCT were followed-up in 6-16 weeks. Reporting of 


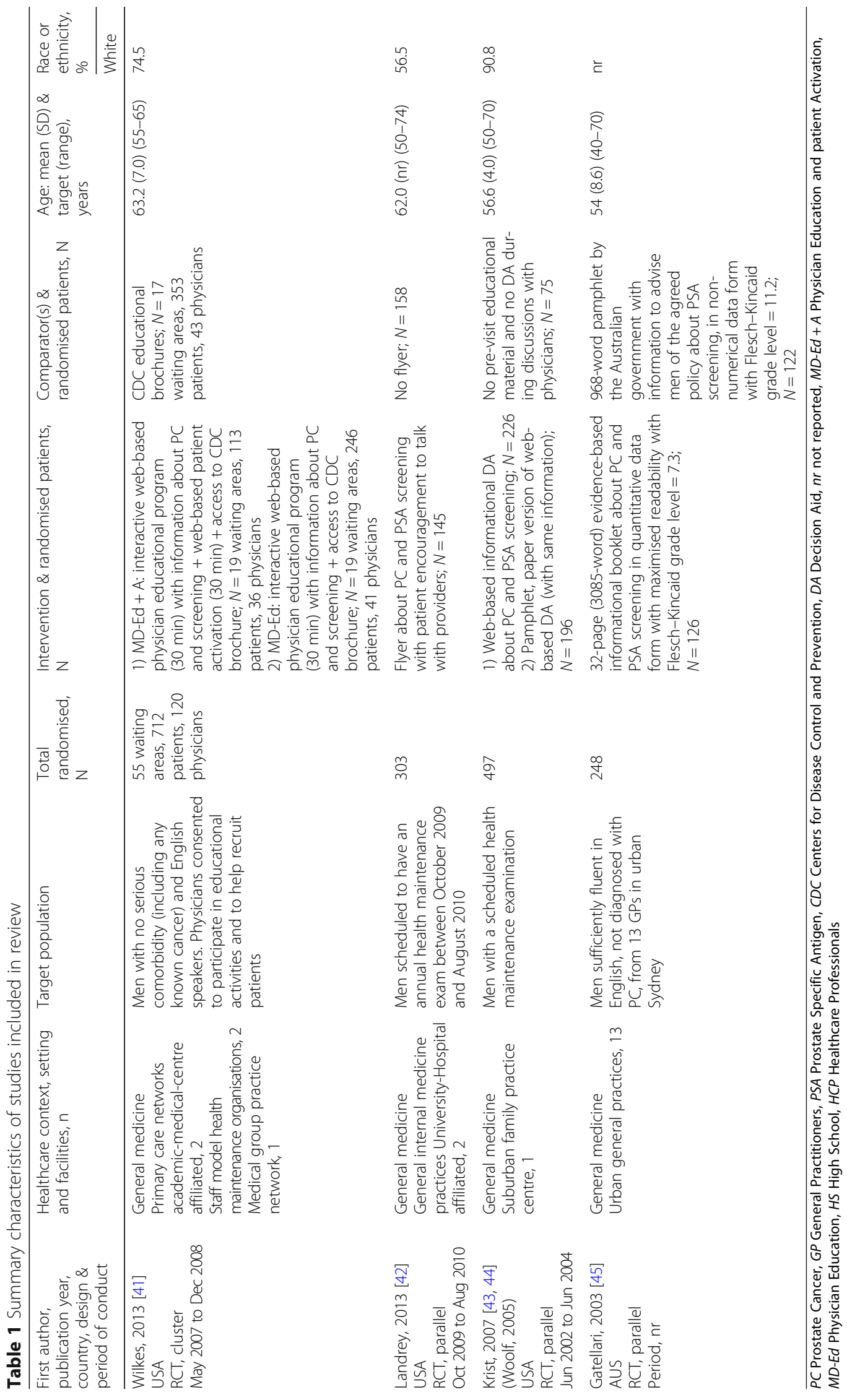




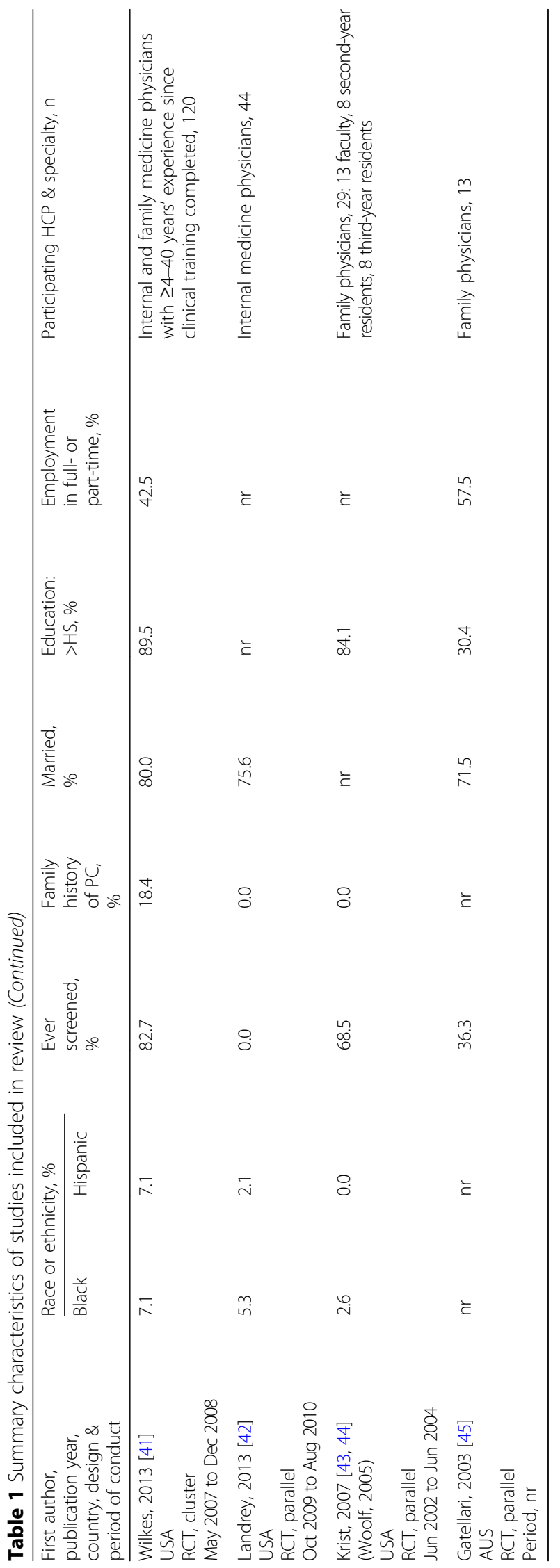


Martínez-González et al. BMC Cancer

(2018) 18:1015

Page 7 of 15

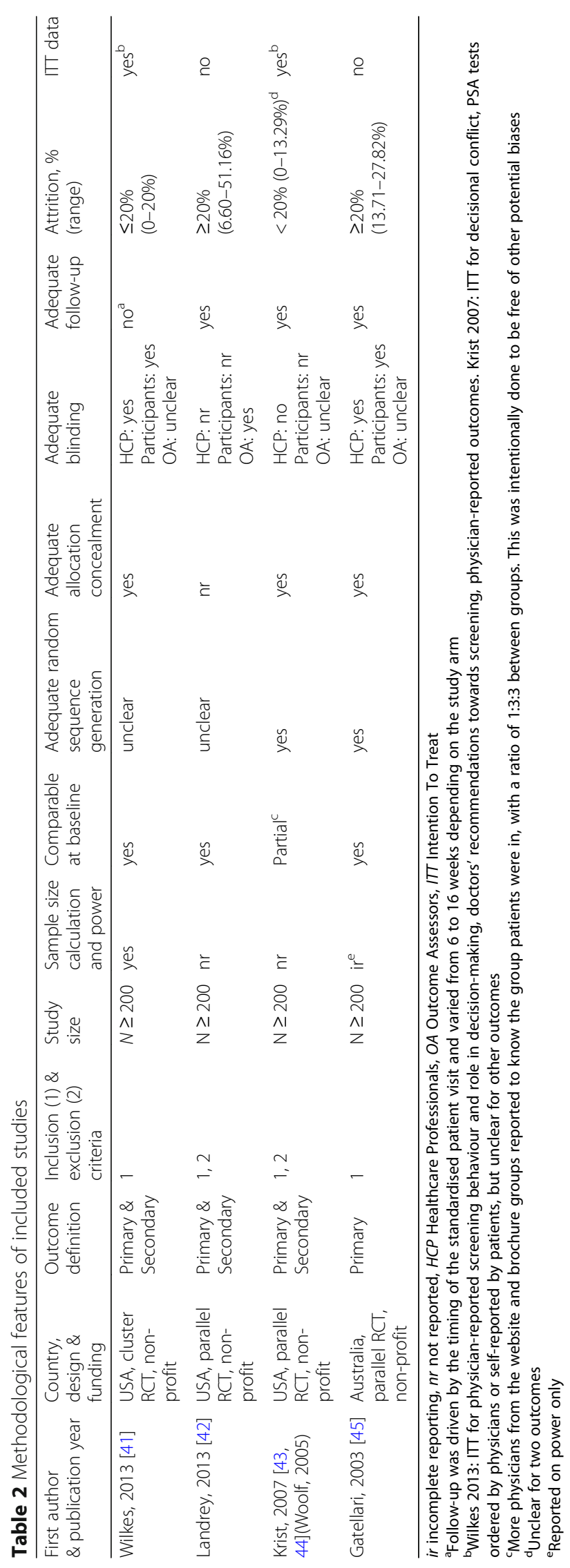


participants' inclusion and exclusion criteria and calculation of sample size and power were adequate in two (50\%) and one (25\%) RCTs respectively. All RCTs measured the interventions' success by definition of primary outcome(s), but data were under-reported for some outcomes in three RCTs. Non-profit institutions funded all RCTs.

\section{Effectiveness of SDM interventions on outcomes}

Five of the nine outcomes of interest were reported in quantitative format (Table 3). Data were sparsely reported across study outcomes limiting the ability to conduct meta-analyses for most cases. Table 4 shows the individual effect estimates from trial data not pooled in meta-analyses.

\section{Affective-Cognitive outcomes}

Knowledge Meta-analysis of two RCTs demonstrated a small but significant effect of SDM, compared to usual care, on improving knowledge of PC (e.g. natural history and risk factors) and screening (SMD 0.23, 95\%CI 0.02 to $0.43, p=0.03 ; \mathrm{I}^{2}=0 \%$ ) (Fig. 2 ). There was no significant heterogeneity between trials $\left(\mathrm{I}^{2}=0 \%, p=0.48\right)$.

Patient satisfaction Individual trial effect estimates showed no significant differences between usual care and SDM (with or without web-based patient activation) intervention groups with respect to the level of satisfaction with medical visits [41].

Risk perception Individual trial effect estimates showed that significantly more men in the SDM group were likely to give a correct estimate of the lifetime risk of developing PC (incidence - correct within 10\%: RR 3.40, 95\%CI 2.16 to 5.36, $p=0.00001$ ) and dying from PC (mortality - correct within 2\%: RR 13.22, 95\%CI 4.30 to 40.66, $\mathrm{p}=0.00001$ ) [45].

\section{Behavioural outcomes}

PSA testing for prostate cancer Meta-analysis of two RCTs demonstrated no significant differences between SDM and usual care in the number of men who preferred or were interested in undergoing individualised
PSA testing, with no significant heterogeneity between trials (RR 1.03, 95\%CI 0.90 to $1.19, p=0.66 ; \mathrm{I}^{2}=0 \%$ ) (Fig. 3).

Individual effect estimates of two trials showed similar results (Table 4). In one RCT, the number of chart-documented patients for whom PSA tests were ordered by clinicians was not significantly different between groups [42]. Another RCT showed no significant differences between SDM intervention groups and usual care with respect to the number of patients who ordered PSA tests [43]. In the same RCT however, physicians reported significantly less men with ordered PSA tests in the SDM intervention groups (Web-based DA vs. Usual Care: RR 0.91, 95\%CI 0.84 to 0.99, $p=0.02$; Paper-based vs. Usual Care: RR 0.90, 95\%CI 0.83 to $0.98, \mathrm{p}=0.02$ ).

In one cluster-RCT, the individual effect estimates showed significantly less physicians in the SDM group with patient activation making recommendations towards PSA testing (RR 0.56, 95\%CI 0.38 to $0.84, p=0.004$ ) [41]. Although the trial showed a similar pattern for the SDM group without patient activation, the effect was only marginally significant (RR $0.74,95 \%$ CI 0.55 to $1.00, p=0.05$ ). Similarly, more physicians in the SDM group with patient activation were more neutral in recommending PSA testing (RR 3.58, 95\%CI 1.59 to $8.06, p=0.002$ ) than physicians in the SDM group with no patient activation (RR $2.45,95 \% \mathrm{CI} 1.04$ to $5.76, p=0.04$ ), although both were statistically significant. In another RCT, the effect estimates suggested a small, but not significant effect that men in the SDM group tend to weigh their views towards reasons in favour of undergoing PSA testing [45].

Decisional conflict Meta-analysis of two RCTs demonstrated no significant differences between SDM and usual care in the level of conflict or uncertainty in making medical decisions (Combination 1, SMD -0.04, $95 \% \mathrm{CI}-0.23$ to $0.15, p=0.66$; Combination 2 , SMD $-0.05,95 \%$ CI -0.24 to $0.14, p=0.59$ ) (Fig. 2). There was no significant heterogeneity between trials $\left(\mathrm{I}^{2}=0 \%\right.$; $=$ 0.59-0.67). However, the effect estimates of one trial showed that men in the SDM group had significantly lower scores of decisional conflict on the factors contributing to

Table 3 Outcomes reported in the included studies

\begin{tabular}{|c|c|c|c|c|c|c|c|c|c|}
\hline \multirow{2}{*}{ Study/Outcome } & \multicolumn{3}{|c|}{ Affective-cognitive } & \multicolumn{3}{|c|}{ Behavioural } & \multicolumn{3}{|c|}{ Health } \\
\hline & Knowledge & $\begin{array}{c}\text { Patient } \\
\text { Satisfaction }\end{array}$ & $\begin{array}{c}\text { Risk } \\
\text { Perception }\end{array}$ & Screening & $\begin{array}{c}\text { Decisional } \\
\text { Conflict }\end{array}$ & $\begin{array}{c}\text { Decisional } \\
\text { Regret }\end{array}$ & $\begin{array}{l}\text { Quality } \\
\text { of Life }\end{array}$ & Symptoms & Mortality \\
\hline Wilkes, 2013 [41] & & & & & & & & & \\
\hline Landrey, 2013 [42] & & & & & & & & & \\
\hline Krist, 2007 [43, 44] (Woolf, 2005) & & & & & & & & & \\
\hline Gatellari, 2003 [45] & & & & & & & & & \\
\hline
\end{tabular}

Green = quantitative data; Yellow = qualitative data; Red = no outcome data 


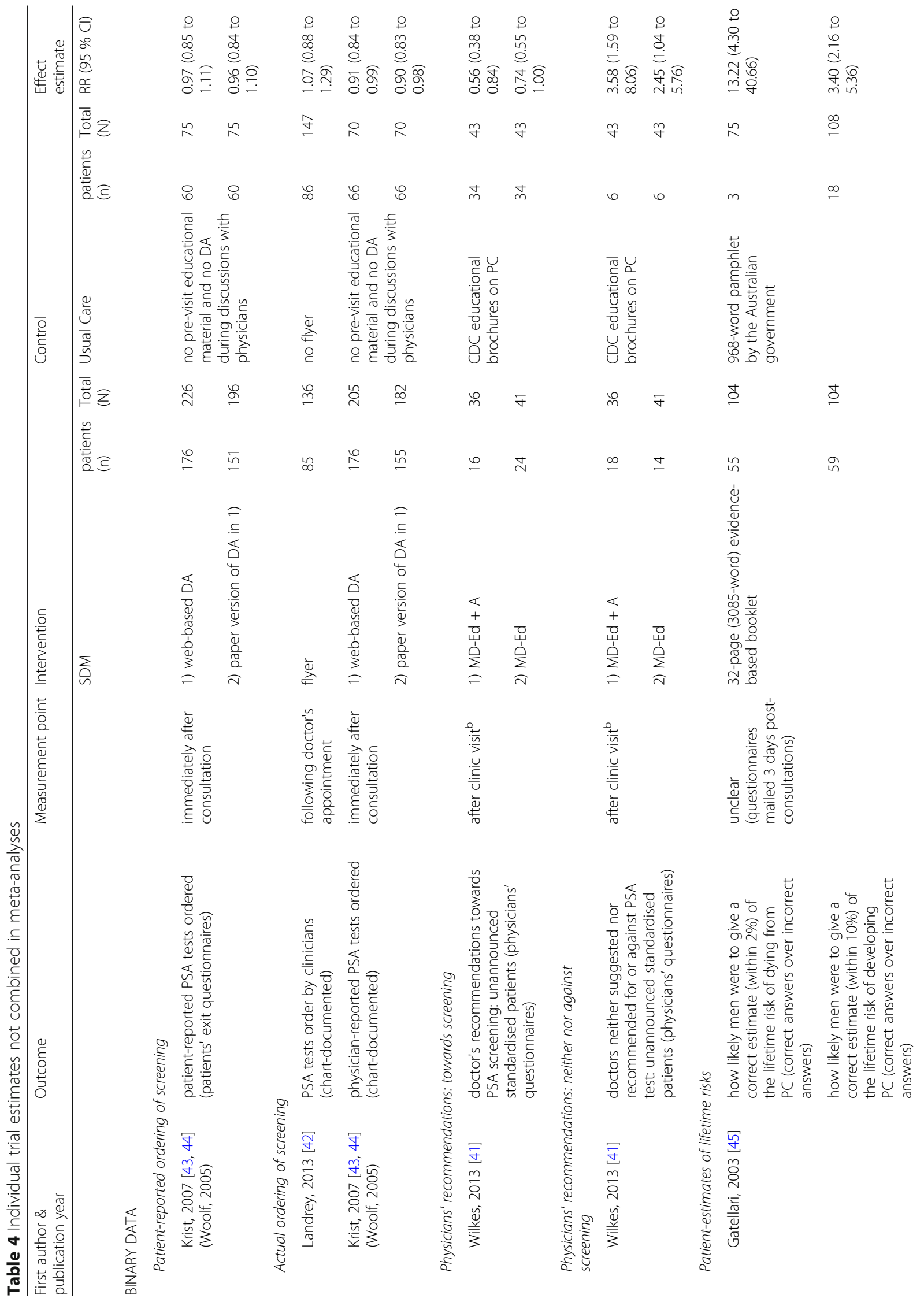


Martínez-González et al. BMC Cancer ～(2018) 18:1015

Page 10 of 15

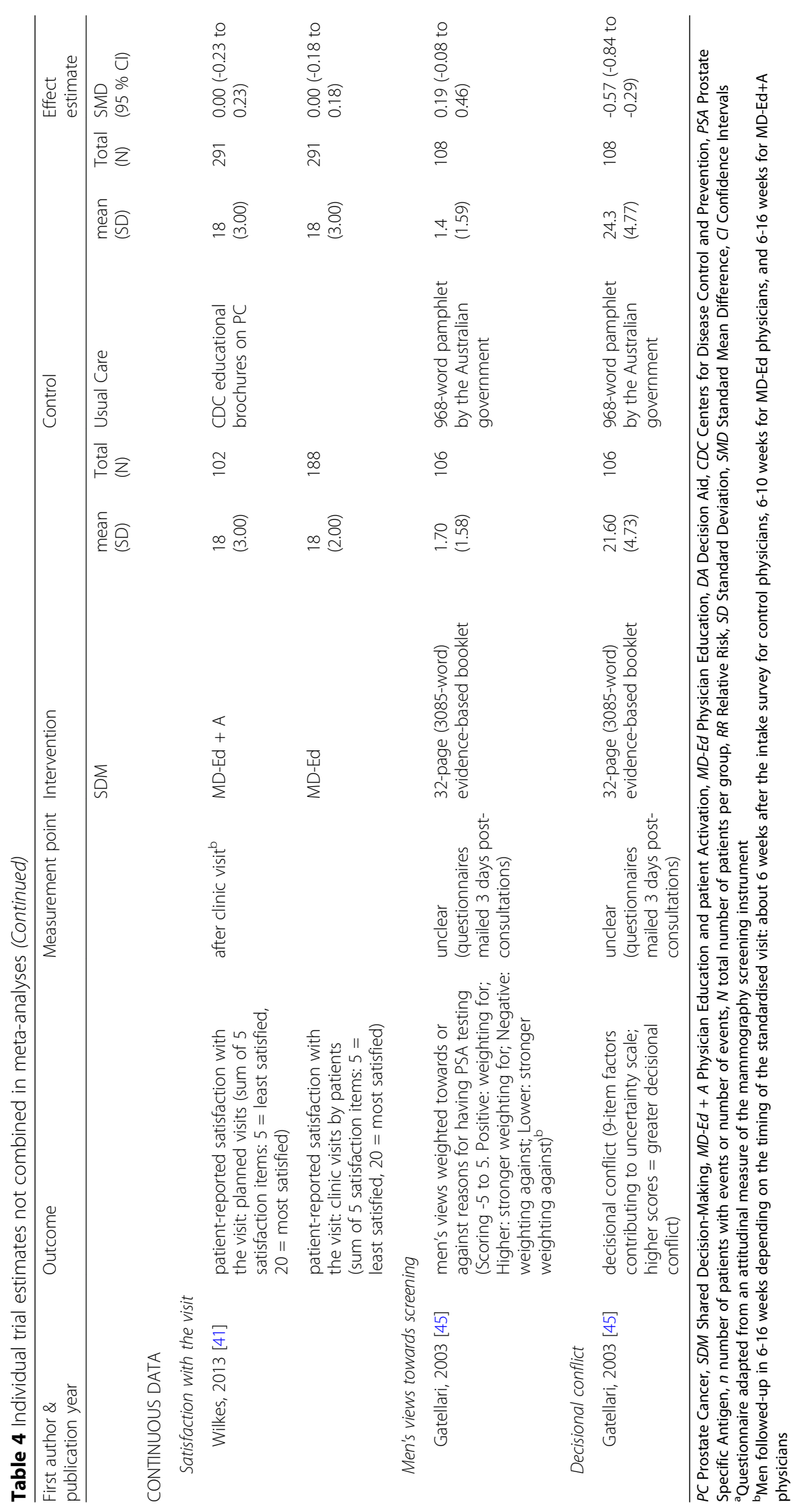




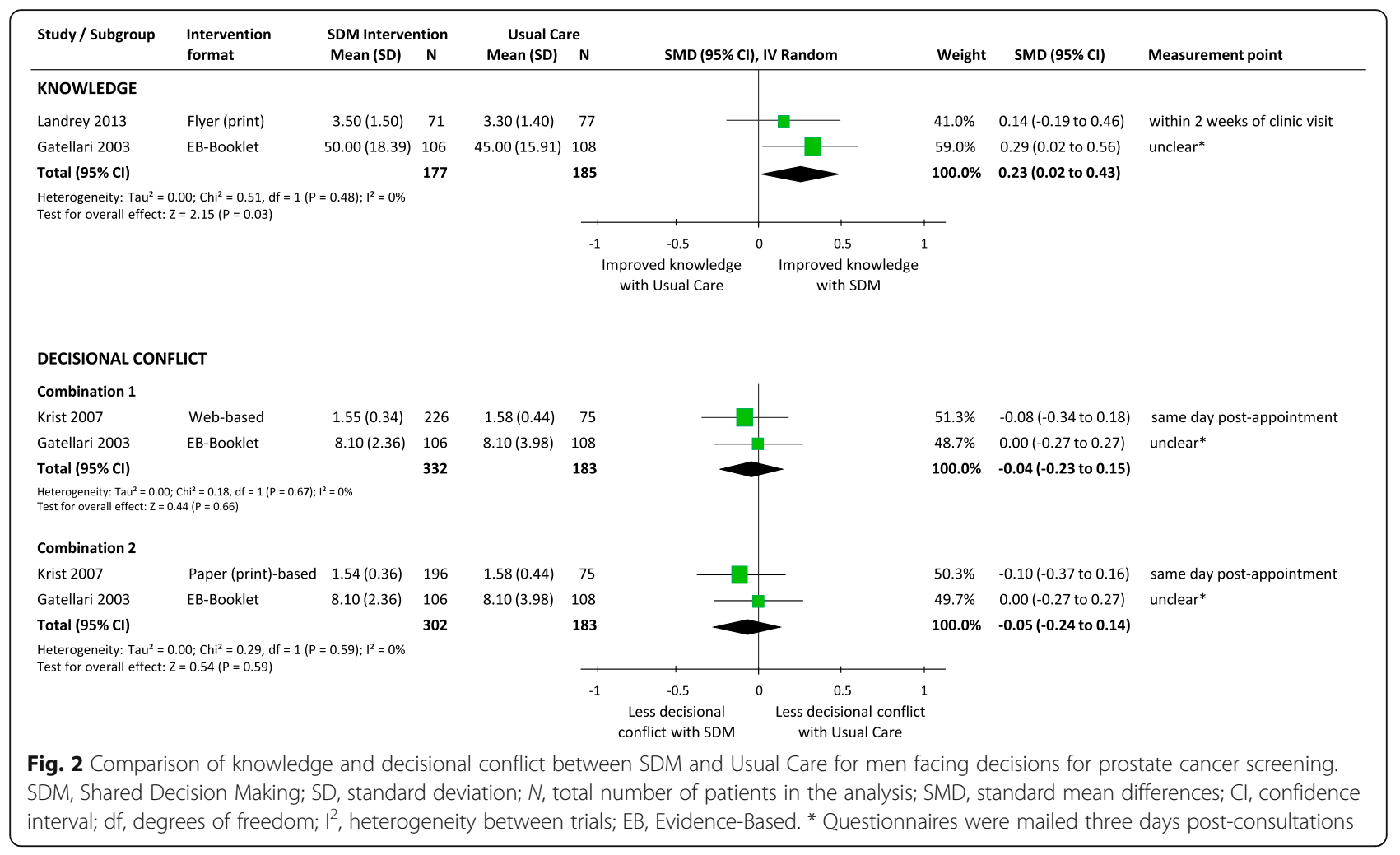

uncertainty subscale (SMD -0.57, 95\%CI -0.84 to $0.29, p<0.0001$ ) (Table 4) [45].

\section{Discussion}

In this systematic review with meta-analysis, the association of SDM with patient outcomes for decisions about PSA testing, as compared to usual care, is inconclusive. SDM is often discussed by policy makers and professional bodies as the best practice model for the physician-patient communication [46], and continues to be highly (guideline-) recommended for medical decisions about PC screening. Many HCP apply elements and features of SDM with a broader scope in their clinical practice, for example using patientcentred communication and patient activation strategies.
We found, however, a very low volume of empirical research fulfilling the criteria for SDM in which various SDM interventions are compared to usual care $(n=4)$.

Although the interventions varied in characteristics and content, the study / interventions were aimed at and contained elements for fostering SDM. The outcomes of interest for this review also varied widely across studies in both quantity and reporting quality. While screening, knowledge and decisional conflict are the most reported SDM process-related outcomes, decisional regret, patient satisfaction or risk perception are scarcely reported, and no study reported on health outcomes. Moreover, no study fulfilled all the methodological quality criteria assessed. Besides sample sizes being modest, the studies

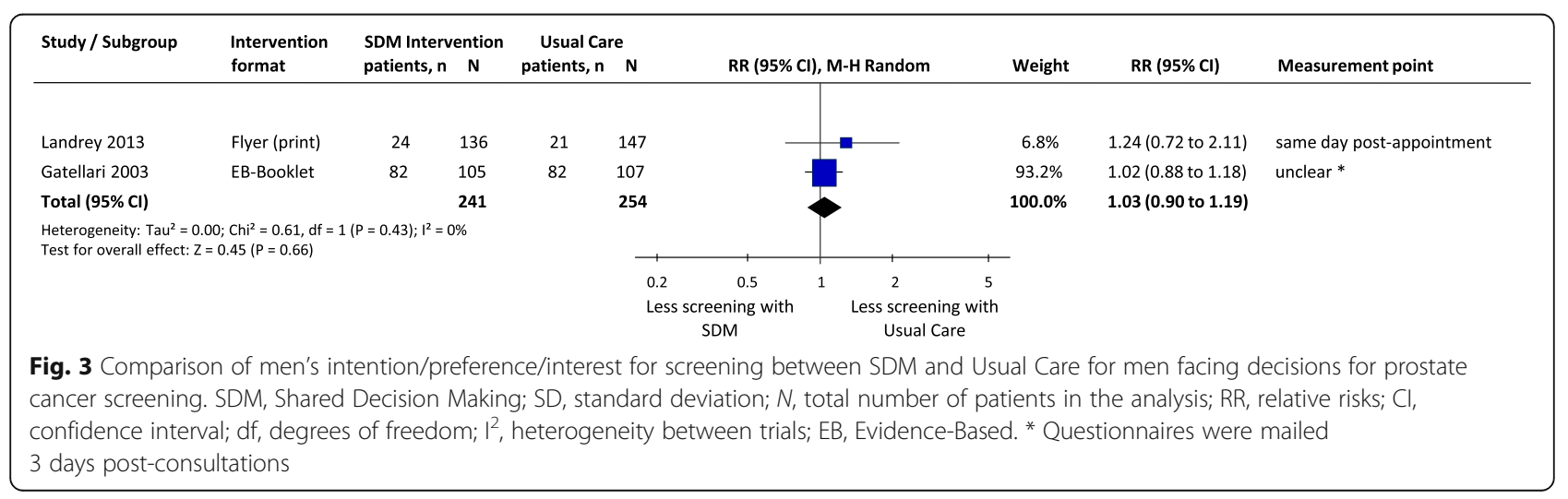


are prone to high risk of bias mainly due to problems in the generation of the random sequence, blinding of outcome assessors, and having an attrition rate of at least $20 \%$ for some outcomes.

The evaluated literature represent in their majority White (76.6\%), middle-aged (range: 54 to 63), married (76.6\%) men from Western countries, mainly the USA, faced with decision-making about individualised PSA testing, who were recruited from general or internal medicine. Most men had PSA testing before the study and a great proportion reported a family history of PC. The participating HCP were family and internal medicine physicians in all studies and surprisingly there were no urologists at all. SDM interventions were mostly developed for and directed at men facing PSA screening decisions, included elements to inform and educate, and were delivered before the decision-making consultations. Finally, the results from this review are based on published data. This review should thus be considered within this context.

Despite this diversity and methodological limitations, our meta-analyses showed a small but significant effect of SDM interventions in improving knowledge of PC and screening, but no significant differences between SDM and usual care in reducing patient participation in PSA testing and decisional conflict. Interestingly, the patients from two RCTs were heavily (68-83\%) screened before enrolment, and a larger than expected proportion of patients reported a family history of PC. This background information may be a factor influencing men's decision for (less) PSA testing and the (lower) likelihood of men starting any decision-making process. Our meta-analyses showed the same direction of effect across studies however, and no significant between-study heterogeneity. Although $53.4 \%(n=8)$ of the individual trial estimates showed no difference between SDM and usual care, $46.7 \%$ $(n=7)$ also suggest an association of SDM with improved outcomes. SDM may reduce or neutralise the tendency of physicians to order or recommend PSA testing and may improve the accuracy of patients' perception of lifetimerisks for PC morbidity and mortality. In the latter [45], around $70 \%$ of men had an education of high school or less and men's estimate of the lifetime risk of dying from PC was highly significant (RR $13.22,95 \%$ CI 4.30 to 40.66 ; $p<0.00001)$. Although lower-literacy has been associated with an individual's overestimation of risk perception [47], high-literacy individuals may also benefit from the educational interventions developed for low-literacy individuals [48]. Furthermore, an increased level of understanding and health knowledge are thought to positively influence decision-making and health behaviours. Remarkably, we found no evidence on the effects of SDM versus usual care on decisional regret and on very important health outcomes including mortality, quality of life, and symptoms. This absence of evidence does not mean that SDM does not have a beneficial effect on patient outcomes at individual or group levels however. Finally, men and physicians were the target of multifaceted interventions in only one RCT [41]. Of note, the included studies reported no cost data.

\section{Future research}

Our findings are applicable to the development of future SDM interventions for decisions about PSA testing and our evaluation of the available evidence highlights a major knowledge gap. Future studies warrant further focus. Only a few studies fulfilled all SDM criteria suggesting that SDM is not yet fully adopted in practice despite guideline recommendations. Some guidance for SDM implementation may therefore be necessary. Whether patient activation without all the mandatory elements of SDM generates the same effects, and whether SDM is cost-effective compared to usual care remain questions for future research. Considering the levels of literacy and understanding may help explain the association between SDM and health outcomes. Future studies also need to address the barriers in the implementation of SDM e.g. physicians' education, time consumption, patients' responsibility and literacy. This could also guide SDM research in other areas of medical practice. Very importantly, the fact that at least $75 \%$ of the patients were Caucasian and married clearly indicates the need for assessing the impact of SDM among other racial and ethnic groups, and across different socio-economic strata. Future research could also help clarifying whether predefinition of study populations based on potential modifiers such as PSA pre-screening and family history of PC can impact the effect of SDM.

Current research could benefit from a more complete description of all interventions and outcome tools. Standardisation of the definition and objectives of SDM could lead to a clearer definition of the outcomes that are best for assessing SDM and its (clinical) effectiveness, and to guide the reasons for outcome selection. The outcomes used to measure the effectiveness of SDM is a topic under debate due to the individualisation of the SDM process. However, to understand the full impact of SDM, one needs to consider the type of decisions made and the extent to which SDM may actually affect health outcomes. Whether patients experience the health outcomes they expect, prefer or to which they feel unfavourably disposed could further guide the investigation of SDM. Future research should therefore address the absence of evidence on the effect of SDM on these outcomes. Future studies should also consider that interventions directed at both $\mathrm{HCP}$ and patients have been 
most effective in improving SDM-related and health outcomes [27]. Finally, larger and more methodologically sound studies could help confirming the findings from this review.

\section{Strengths and limitations}

To our knowledge, this is the first systematic review about SDM compared to usual care for decisions about PC screening. Compared to other reviews [27], ours evaluates the effect of (higher quality) SDM implementation on both SDM-related and patient outcomes with a focus on PC testing. We searched for international literature with no restriction on countries or type of HCP. Our review also benefits from the inclusion of RCTs thus allowing the estimation of causal effects with lower risk of bias. In addition, our comprehensive search strategy comprised terms relevant to decision-making including SDM and DAs. We included studies published in English only and although the academic databases were searched up to March 2015, we made considerable efforts to identify all relevant studies. We also searched for grey literature by accessing the records retrieved from several sources between February and August 2016. By contacting authors between 2015 and 2017, we increased the chances of identifying more of the latest literature and full-texts with more complete data. Apart from using thorough electronic and manual searches, we conducted in-duplicate screening and study selection by applying a broad inclusion criteria at screening and full-text evaluation, and considered studies regardless of whether a specific decision was promoted.

We restricted our review to studies that fulfilled all SDM framework criteria [31] because of the continuing gaps in the conceptualisation and implementation of SDM. Our SDM framework is based on the SDM model by Charles et al. [29], the most prominent approach of viewing SDM with only one SDM concept [49] supporting the principle of bi-directional deliberation in keeping with Elwyn et al. [30]. This rigorous and focused approach allowed us to identify studies that integrated the key elements of SDM. The assessment was based on reported data, which cannot exclude the possibility of underreported SDM characteristics in other studies. Nevertheless, our review represents the results of studies with higher quality SDM implementation. Furthermore, to increase the precision of the effect estimates, we incorporated meta-analyses where possible, and assessed the risk of bias of individual studies.

The results from our systematic review are mainly limited by the quantity and methodological quality of the available literature. Only a few studies fulfilled the SDM framework and compared SDM to usual care. In addition, there is a dearth of data for nearly half of the outcomes of interest and the outcomes varied in the measurements used and reporting quality. The studies tend to focus primarily on SDM process-related outcomes and do not report on health outcomes. Thus, the few meta-analyses that we could incorporate contained two studies at most. Furthermore, the interventions' content, especially usual care, were not fully described; and not only the studies were prone to high risk of bias but sample sizes were generally modest.

\section{Conclusions}

A few studies that currently fulfil the criteria for SDM also assess the comparative effectiveness of SDM with usual care for decisions about PC screening. The studies comprise various SDM-fostering interventions and outcomes of variable reporting quality. SDM may improve knowledge and patient-perception of risk, and may reduce the tendency of physicians to recommend PSA testing. SDM may be similar to usual care in reducing patient participation in PSA testing, and in improving patient satisfaction and decisional conflict. There is insufficient evidence to support a clear association of SDM on patient-important and SDM-related outcomes for decisions about PSA testing. Future research needs to assess the clinical effectiveness of SDM using well-defined SDM interventions and outcomes. It should address the absence of evidence especially of health outcomes and costs.

\section{Additional files}

Additional file 1: PRISMA checklist. (DOCX $43 \mathrm{~kb}$ )

Additional file 2: Search strategy for OVID Medline. (DOCX 18 kb)

\section{Acknowledgements}

We are grateful to Martina Gösteli, librarian from the main library of the University of Zurich, for her assistance with the search strategies. We thank Stefan Markun for his help in the first stage of the systematic review and Fabio Valeri for discussions on the statistics from the studies selected. We are grateful to Mark Fraser for copy editing and proofreading our manuscript.

\section{Availability of data and materials}

All data generated is included in the present article. Additional supporting material is contained in Additional files 1 and 2.

\section{Funding}

This study had no external funding and the authors received no specific funding for this work.

\section{Authors' contributions}

NAMG, SNJ and OS conceived and designed the review. NAMG, SNJ, OS and AP carried out the screening and selection of studies. NM and AP carried out the appraisal of study quality, data extraction, and the verification of data. NM performed the analyses, communicated the results and wrote the manuscript. All authors contributed to improving the manuscript, read and approved the version of the manuscript to be published. All authors take responsibility for appropriate content.

Ethics approval and consent to participate

This review does not need ethics approval and consent to participate because it only synthesises previously published results. 


\section{Consent for publication}

Not applicable.

\section{Competing interests}

The authors declare that they have no competing interests.

\section{Publisher's Note}

Springer Nature remains neutral with regard to jurisdictional claims in published maps and institutional affiliations.

Received: 6 November 2017 Accepted: 3 September 2018 Published online: 22 October 2018

\section{References}

1. Ferlay J, Soerjomataram I, Dikshit R, Eser S, Mathers C, Rebelo M, Parkin DM, Forman D, Bray F. Cancer incidence and mortality worldwide: sources, methods and major patterns in GLOBOCAN 2012. Int J Cancer. 2015;136(5):E359-86.

2. Center MM, Jemal A, Lortet-Tieulent J, Ward E, Ferlay J, Brawley O, Bray F. International variation in prostate Cancer incidence and mortality rates. Eur Urol. 2012;61(6):1079-92.

3. Kicinski M, Vangronsveld J, Nawrot TS. An epidemiological reappraisal of the familial aggregation of prostate cancer: a meta-analysis. PLoS One. 2011; 6(10):e27130.

4. Melia J. Part 1: the burden of prostate cancer, its natural history, information on the outcome of screening and estimates of ad hoc screening with particular reference to England and Wales. BJU Int. 2005;95(Suppl 3):4-15.

5. Schroder FH, Hugosson J, Roobol MJ, Tammela TL, Ciatto S, Nelen V, Kwiatkowski M, Lujan M, Lilja H, Zappa M, et al. Screening and prostatecancer mortality in a randomized European study. N Engl J Med. 2009; 360(13):1320-8.

6. Loeb S, Bjurlin MA, Nicholson J, Tammela TL, Penson DF, Carter HB, Carroll P, Etzioni R. Overdiagnosis and overtreatment of prostate cancer. Eur Urol. 2014;65(6):1046-55.

7. Pinsky PF, Prorok PC, Yu K, Kramer BS, Black A, Gohagan JK, Crawford ED, Grubb $\mathrm{RL}$, Andriole GL. Extended mortality results for prostate cancer screening in the PLCO trial with median follow-up of 15 years. Cancer. 2017:123(4):592-9.

8. Andriole GL, Crawford ED, Grubb RL 3rd, Buys SS, Chia D, Church TR, Fouad MN, Isaacs C, Kvale PA, Reding DJ, et al. Prostate cancer screening in the randomized prostate, lung, colorectal, and ovarian Cancer screening trial: mortality results after 13 years of follow-up. J Natl Cancer Inst. 2012;104(2):125-32.

9. Sandblom G, Varenhorst E, Rosell J, Lofman O, Carlsson P. Randomised prostate cancer screening trial: 20 year follow-up. BMJ. 2011;342:d1539.

10. Schroder FH, Hugosson J, Roobol MJ, Tammela TL, Zappa M, Nelen V, Kwiatkowski M, Lujan M, Maattanen L, Lilja H, et al. Screening and prostate cancer mortality: results of the European randomised study of screening for prostate Cancer (ERSPC) at 13 years of follow-up. Lancet. 2014;384(9959):2027-35.

11. Schroder FH, Hugosson J, Carlsson S, Tammela T, Maattanen L, Auvinen A, Kwiatkowski M, Recker F, Roobol MJ. Screening for prostate cancer decreases the risk of developing metastatic disease: findings from the European randomized study of screening for prostate Cancer (ERSPC). Eur Urol. 2012;62(5):745-52.

12. Labrie F, Candas B, Cusan L, Gomez JL, Belanger A, Brousseau G, Chevrette E, Levesque J. Screening decreases prostate cancer mortality: 11-year followup of the 1988 Quebec prospective randomized controlled trial. Prostate. 2004;59(3):311-8.

13. Donovan JL, Hamdy FC, Lane JA, Mason M, Metcalfe C, Walsh E, Blazeby JM, Peters TJ, Holding P, Bonnington S, et al. Patient-reported outcomes after monitoring, surgery, or radiotherapy for prostate cancer. N Engl J Med. 2016;375(15):1425-37.

14. Heijnsdijk EAM, de Carvalho TM, Auvinen A, Zappa M, Nelen V, Kwiatkowski M, Villers A, Páez A, Moss SM, Tammela TL, et al. Cost-effectiveness of prostate cancer screening: a simulation study based on ERSPC data. J Natl Cancer Inst. 2015;107(1):dju366.

15. Grossman DC, Curry SJ, Owens DK, Bibbins-Domingo K, Caughey AB, Davidson KW, Doubeni CA, Ebell M, Epling JW Jr, Kemper AR, et al. Screening for prostate Cancer: US preventive services task force recommendation statement. JAMA. 2018;319(18):1901-13.

16. Fenton JJ, Weyrich MS, Durbin S, Liu Y, Bang H, Melnikow J. Prostate-specific antigen-based screening for prostate cancer: evidence report and systematic review for the US preventive services task force. JAMA. 2018; 319(18):1914-31.

17. Mottet N, Bellmunt J, Bolla M, Briers E, Cumberbatch MG, De Santis M, Fossati N, Gross T, Henry AM, Joniau S, et al. EAU-ESTRO-SIOG guidelines on prostate Cancer. Part 1: screening, diagnosis, and local treatment with curative intent. Eur Urol. 2017;71(4):618-29.

18. Harris RP, Wilt TJ, Qaseem A. A value framework for cancer screening: advice for high-value care from the American college of physicians. Ann Intern Med. 2015;162(10):712-7.

19. Carter HB, Albertsen PC, Barry MJ, Etzioni R, Freedland SJ, Greene $K L_{\text {, }}$ Holmberg L, Kantoff P, Konety BR, Murad MH, et al. Early detection of prostate cancer: AUA guideline. J Urol. 2013;190(2):419-26.

20. Gondos A, Krilaviciute A, Smailyte G, Ulys A, Brenner H. Cancer surveillance using registry data: results and recommendations for the Lithuanian national prostate cancer early detection programme. Eur J Cancer. 2015; 51(12):1630-7.

21. UK National Screening Committee: Recommendation on prostate cancer screening/PSA testing; 2018. [Available from: https://legacyscreening.phe. org.uk/prostatecancer].

22. Parker C, Gillessen S, Heidenreich A, Horwich A. Cancer of the prostate: ESMO clinical practice guidelines for diagnosis, treatment and follow-up. Ann Oncol. 2015;26(Suppl 5):v69-77.

23. Bell N, Connor Gorber S, Shane A, Joffres M, Singh H, Dickinson J, Shaw E, Dunfield L, Tonelli M. Recommendations on screening for prostate cancer with the prostate-specific antigen test. Can Med Assoc J. 2014;186(16):1225-34.

24. Carlsson S, Leapman M, Carroll P, Schroder F, Albertsen PC, llic D, Barry M, Frosch DL, Vickers $A$. Who and when should we screen for prostate cancer? interviews with key opinion leaders. BMC Med. 2015;13:288.

25. Stiggelbout AM, Van der Weijden T, De Wit MP, Frosch D, Legare F, Montori VM, Trevena L, Elwyn G. Shared decision making: really putting patients at the Centre of healthcare. BMJ. 2012;344:e256.

26. Coulter A, Parsons S, Askham J. Health systems and policy analysis. Policy brief: where are the patients in decision-making about their own care? In. European Observatory on Health Systems and Policies, WHO Regional Office for Europe: Copenhagen; 2008.

27. Legare F, Stacey D, Turcotte S, Cossi MJ, Kryworuchko J, Graham ID, Lyddiatt A, Politi MC, Thomson R, Elwyn G, et al. Interventions for improving the adoption of shared decision making by healthcare professionals. Cochrane Database Syst Rev. 2014;(9):CD006732.

28. Mulley AG, Trimble C, Elwyn G. Stop the silent misdiagnosis: patients' preferences matter. BMJ. 2012;345:e6572.

29. Charles C, Gafni A, Whelan T. Decision-making in the physician-patient encounter: revisiting the shared treatment decision-making model. Soc Sci Med. 1999:49(5):651-61.

30. Elwyn G, Frosch D, Rollnick S. Dual equipoise shared decision making: definitions for decision and behaviour support interventions. Implement Sci. 2009;4(1):75.

31. Martinez-Gonzalez NA, Plate A, Senn O, Markun S, Rosemann T, NeunerJehle $\mathrm{S}$. Shared decision-making for prostate cancer screening and treatment: a systematic review of randomised controlled trials. Swiss Med Wkly. 2018;148:w14584.

32. Stacey D, Legare F, Col NF, Bennett CL, Barry MJ, Eden KB, Holmes-Rovner M, Llewellyn-Thomas H, Lyddiatt A, Thomson R, et al. Decision aids for people facing health treatment or screening decisions. Cochrane Database Syst Rev. 2014:(1):CD001431.

33. Egger M, Smith GD, Altman DG. Principles of and procedures for systematic reviews. In: Egger M, Smith GD, Altman DG, editors. Systematic reviews in health care. 2nd ed. London: BMJ Publishing Group; 2008. p. 23-42.

34. Higgins JPT GS, (editors): Cochrane Handbook for Systematic Reviews of Interventions Version 5.1.0 [updated 2011]: The Cochrane Collaboration, 2009. Available from https://training.cochrane.org/handbook.

35. Liberati A, Altman DG, Tetzlaff J, Mulrow C, Gotzsche PC, loannidis JP, Clarke M, Devereaux PJ, Kleijnen J, Moher D. The PRISMA statement for reporting systematic reviews and meta-analyses of studies that evaluate health care interventions: explanation and elaboration. PLoS Med. 2009;6(7):e1000100.

36. Charles C, Gafni A, Whelan T. Shared decision-making in the medical encounter: what does it mean? (or it takes at least two to tango). Soc Sci Med. 1997:44(5):681-92.

37. Elwyn G, Frosch D, Thomson R, Joseph-Williams N, Lloyd A, Kinnersley P, Cording E, Tomson D, Dodd C, Rollnick S, et al. Shared decision making: a model for clinical practice. J Gen Intern Med. 2012;27(10):1361-7. 
38. Shay LA, Lafata JE. Where is the evidence? A systematic review of shared decision making and patient outcomes. Med Decis Mak. 2015;35(1):114-31.

39. Juni P, Witschi A, Bloch R, Egger M. The hazards of scoring the quality of clinical trials for meta-analysis. JAMA. 1999;282(11):1054-60

40. Higgins JP, Thompson SG. Quantifying heterogeneity in a meta-analysis. Stat Med. 2002;21(11):1539-58.

41. Wilkes MS, Day FC, Srinivasan M, Griffin E, Tancredi DJ, Rainwater JA, Kravitz RL, Bell DS, Hoffman JR. Pairing physician education with patient activation to improve shared decisions in prostate cancer screening: a cluster randomized controlled trial. Ann Fam Med. 2013;11(4):324-34.

42. Landrey AR, Matlock DD, Andrews L, Bronsert M, Denberg T. Shared decision making in prostate-specific antigen testing: the effect of a mailed patient flyer prior to an annual exam. J Prim Care Community Health. 2013; 4(1):67-74.

43. Krist AH, Woolf SH, Johnson RE, Kerns JW. Patient education on prostate cancer screening and involvement in decision making. Ann Fam Med. 2007; 5(2):112-9.

44. Woolf SH, Krist AH, Johnson RE, Stenborg PS. Unwanted control: how patients in the primary care setting decide about screening for prostate cancer. Patient Educ Couns. 2005;56(1):116-24.

45. Gattellari M, Ward JE. Does evidence-based information about screening for prostate cancer enhance consumer decision-making? a randomised controlled trial. J Med Screen. 2003;10(1):27-39.

46. van der Weijden T, Post $H$, Brand PLP, van Veenendaal $H$, Drenthen $T$, van Mierlo LA, Stalmeier P, Damman OC, Stiggelbout A. Shared decision making, a buzz-word in the Netherlands, the pace quickens towards nationwide implementation. Z Evid Fortbild Qual Gesundhwes. 2017;123-124:69-74.

47. Reyna VF, Nelson WL, Han PK, Dieckmann NF. How numeracy influences risk comprehension and medical decision making. Psychol Bull. 2009;135(6):943-73.

48. DeWalt DA, Malone RM, Bryant ME, Kosnar MC, Corr KE, Rothman RL, Sueta CA, Pignone MP. A heart failure self-management program for patients of all literacy levels: a randomized, controlled trial. BMC Health Serv Res. 2006;6:30.

49. Makoul G, Clayman ML. An integrative model of shared decision making in medical encounters. Patient Educ Couns. 2006;60(3):301-12.

Ready to submit your research? Choose BMC and benefit from:

- fast, convenient online submission

- thorough peer review by experienced researchers in your field

- rapid publication on acceptance

- support for research data, including large and complex data types

- gold Open Access which fosters wider collaboration and increased citations

- maximum visibility for your research: over $100 \mathrm{M}$ website views per year

At $\mathrm{BMC}$, research is always in progress.

Learn more biomedcentral.com/submissions 